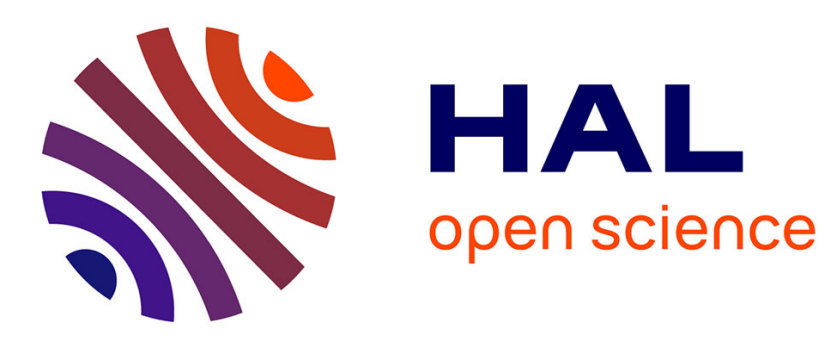

\title{
Self-induced laser line sweeping and self-pulsing in double-clad fiber lasers in Fabry-Perot and unidirectional ring cavities
}

Pavel Peterka, P. Navrátil, Bernard Dussardier, R. Slavik, P. Honzatko, Václav Kubeček

\section{To cite this version:}

Pavel Peterka, P. Navrátil, Bernard Dussardier, R. Slavik, P. Honzatko, et al.. Self-induced laser line sweeping and self-pulsing in double-clad fiber lasers in Fabry-Perot and unidirectional ring cavities. SPIE Photonics Europe, Apr 2012, Brussels,, Belgium. pp.843309, 10.1117/12.924298 hal-00731855

\section{HAL Id: hal-00731855 \\ https://hal.science/hal-00731855}

Submitted on 14 Sep 2012

HAL is a multi-disciplinary open access archive for the deposit and dissemination of scientific research documents, whether they are published or not. The documents may come from teaching and research institutions in France or abroad, or from public or private research centers.
L'archive ouverte pluridisciplinaire HAL, est destinée au dépôt et à la diffusion de documents scientifiques de niveau recherche, publiés ou non, émanant des établissements d'enseignement et de recherche français ou étrangers, des laboratoires publics ou privés. 


\title{
Self-induced laser line sweeping and self-pulsing in double-clad fiber lasers in Fabry-Perot and unidirectional ring cavities
}

\author{
Pavel Peterka $^{* a}$, Petr Navrátil $^{\mathrm{a}, \mathrm{b}}$, Bernard Dussardier $^{\mathrm{c}}$, Radan Slavík ${ }^{\mathrm{a}, \mathrm{d}}$, Pavel Honzátko ${ }^{\mathrm{a}}$, \\ and Václav Kubeček ${ }^{\mathrm{b}}$

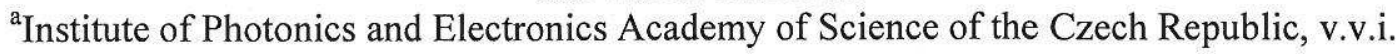 \\ Chaberská 57, 18251 Prague, Czech Republic; \\ ${ }^{\mathrm{b}}$ Czech Technical University, Faculty of Nuclear Sciences and Physical Engineering \\ Břehová 7, 11519 Prague, Czech Republic; \\ ${ }^{c}$ Laboratoire de Physique de la Matière Condensée, Université de Nice-Sophia-Antipolis, CNRS \\ UMR 6622, Avenue Joseph Vallot, Parc Valrose, 06108 NICE CEDEX 2, France; \\ ${ }^{\mathrm{d}}$ Optoelectronics Research Centre, University of Southampton \\ SO17 1BJ, Southampton, United Kingdom
}

\begin{abstract}
Rare-earth doped fiber lasers are subject to instabilities and various self-pulsed regimes that can lead to catastrophic damage of their components. An interesting self-pulsing regime accompanied with laser wavelength drift with time is the so called self-induced laser line sweeping (SLLS). Despite the early observations of the SLLS in solid-state ruby lasers, in fiber lasers it was first time mentioned in literature only in 2009 where such a laser wavelength drift with time was observed in a relatively broad range of about $1076-1084 \mathrm{~nm}$ in ring ytterbium-doped fiber laser (YDFL). The main characteristic of the SLLS is the scanning of the laser wavelength from shorter to longer wavelength, spanning over large interval of several nanometers, and instantaneous bounce backward. The period of this sweeping is usually quite long, of the order of seconds. This spectacular effect was attributed to spatial-hole burning caused by standing-wave in the laser cavity. In this paper we present experimental investigation of the SLLS in YDFLs in Fabry-Perot cavity and ring cavities. The SLLS was observed also in erbium-doped fiber laser around $1560 \mathrm{~nm}$. We present for the first time observation of the laser wavelength sweep in reverse direction, i.e., from longer towards shorter wavelengths. It was observed in YDFL around $1080 \mathrm{~nm}$.
\end{abstract}

Keywords: ytterbium, erbium, fiber lasers, ring cavity, linear cavity, long-period fiber grating; cladding pumping, tunable laser

\section{INTRODUCTION}

Rare-earth doped fiber lasers are subject to instabilities and various self-pulsation regimes that can lead to catastrophic damage of their components [1-5]. The self-pulsation regimes have been attributed, e.g., to reabsorption in an unpumped part of the active fiber, Raman and Brillouin scattering processes, ion pairs formation and external perturbations like pump instabilities. One of the self-pulsing regimes is the so-called self-induced laser line sweeping (SLLS). This description of the pulsed regime reflects the fact that the self-pulsing coexists with spectacular laser line drift with time. In fiber lasers, this effect was mentioned for the first time in literature in 2009 where such a laser wavelength drift with time was observed in a relatively broad range of about $1076-1084 \mathrm{~nm}$ in a ring ytterbium-doped fiber laser (YDFL) [6]. Origin of the SLLS in this fiber-ring laser was explained in [7]. The SLLS effect in Fabry-Perot fiber laser cavities was independently reported by two groups [8] and [9].

\footnotetext{
"peterka@ufe.cz; phone +420 26773 527; fax +420 284680 222; www.ufe.cz
} 
The SLLS can be explained by a spatial-hole burning (SHB) in the active medium of the laser cavity. In FabryPerot laser the SHB is caused by strong interference of narrow-linewidth, contra-propagating beams inside the cavity. Superposition of the bouncing beams inside the Fabry-Perot cavity creates an interference pattern of nodes and antinodes in the YDF and consequently it would make a grating of higher signal gain at nodes and lower gain at antinodes. This grating then causes shift of the longitudinal laser modes to the modes with better spatial overlap of higher gain areas in the YDF. In contrast to Fabry-Perot cavities, in the case of the ring laser the standing wave responsible for the SLLS is created by interference of the laser signal wave and its single weak reflection at the output coupler. It means that the interference between only two counter-propagating laser signal waves in the ring YDFL may lead to sufficient modulation of the ytterbium population inversion and create the dynamical grating responsible for the SLLS. From the spectral point of view the self-written grating exhibit itself as an inhomogeneous gain broadening. The gain/loss spectrum is then modulated by a function proportional to $\operatorname{sinc}\left(C\left(\lambda-\lambda_{0}\right)\right)$ where the constant $C$ depends primarily on the grating length and $\lambda_{0}$ is the wavelength of the narrow-bandwidth, high-power beam. Such a spectral modulation is known from applications in erbium doped fiber lasers, e.g., narrowing and stabilization of the linewidth of erbium doped fiber laser can be achieved by SHB in twin-core fiber with cores doped with erbium [10]. Modulation of the laser cavity spectral loss by the function $\operatorname{sinc}\left(C\left(\lambda-\lambda_{0}\right)\right)$ is apparent, e.g., from results of detailed numerical modeling of the laser with erbium-doped twin-core fiber tracking filter in [10]. Similarity of the sweeping dynamics in YDFL with early observations of SLLS in solid-state ruby lasers was noticed in [11]. In ruby lasers the SHB leads to self-sustained relaxation oscillations and therefore the laser generation occurs in the spiking mode. Lobach et al. [11] observed square root dependence of both the sweep rate and frequency of self-pulsation on the laser output power.

In the paper we present experimental investigation of the SLLS in Fabry-Perot cavity and ring cavities. We present for the first time observation of the laser wavelength sweep in reverse direction, i.e., from longer towards shorter wavelengths. It was observed in YDFL in Fabry-Perot configuration and emitting around $1080 \mathrm{~nm}$. We have observed two mutually reversed regimes of SLLS also in erbium-doped fiber laser (EDFL) around $1560 \mathrm{~nm}$.

\section{EXPERIMENTAL SETUPS OF FIBER LASERS}

We have studied the effect SLLS in YDFLs in Fabry-Perot and ring laser setups according to Fig. 1. The gain medium was a double-clad YDF (Liekki-nLight Yb1200-6/125DC) with nominal $2.6 \mathrm{~dB} / \mathrm{m}$ peak absorption in the inner cladding and $1200 \mathrm{~dB} / \mathrm{m}$ in the core. The inner cladding has an octagonal shape with $125 \mu \mathrm{m}$ average diameter and the core has the diameter of $6 \mu \mathrm{m}$ and numerical aperture of 0.13 . The outer cladding is made from low refractive index polymer. The laser output of the Fabry-Perot laser was obtained from perpendicularly cleaved fiber ends and in the case of the ring YDFL the output was obtained from $80 \%$ branch of a fused optical fiber coupler. A pigtailed optical fiber isolator was inserted into the ring cavity to ensure unidirectional propagation of the laser signal. In the experiments, we used one multimode-pump laser diode with maximum output power of $6 \mathrm{~W}$ at around $975 \mathrm{~nm}$. In order to select the operating wavelength of the ring laser we inserted long-period fiber gratings (LPFGs) into the resonator. Insertion of the LPFGs into the ring resonator leads to modification of the net spectral gain of the laser and in such a way the laser wavelength is selected [6]. The LPFGs were inscribed onto the passive fiber (Fibercore PS1250/1500) by $\mathrm{CO}_{2}$ laser. The LPFG No. 1 has the grating period of $179 \mu \mathrm{m}$ and length of $18 \mathrm{~mm}$ providing a band stop filter centered at $1056 \mathrm{~nm}$ with $3 \mathrm{~dB}$ and 10 $\mathrm{dB}$ suppression width of 30 and $19 \mathrm{~nm}$, respectively. The grating period and length of the LPFG No. 2 are $179 \mu \mathrm{m}$ and $14 \mathrm{~mm}$, respectively, and its band stop filter center is at $1089 \mathrm{~nm}$ with $3 \mathrm{~dB}$ and $10 \mathrm{~dB}$ suppression width of 31 and 19 nm, respectively.

\section{RESULTS AND DISCUSSION}

Fiber lasers under test were characterized in terms of their output power, laser spectrum and temporal dynamics. The output power was measured directly from the output fibers as shown in Fig. 1 using a thermopile power detector. Information about laser spectrum and its temporal dynamics was retrieved from one of the unused pump branches of the signal and pump combiner. Two combiners were used: one that combines six pump fibers and one signal fiber while the other combines two pump and one signal fiber into one double-clad fiber with $125 \mu \mathrm{m}$ outer diameter and single mode core at the laser wavelength. In both combiners, the signal fiber was single mode at the laser signal wavelengths and the 
pump branches fibers were made out of multimode fibers with $105 \mu \mathrm{m}$ and $125 \mu \mathrm{m}$ diameter of the core and cladding, respectively. The signal transmission of the combiner is about $90 \%$ and part of the lost signal appears in the pump branches. Therefore, the unused pump branch(es) can be used with advantage for spectrum and temporal dynamics monitoring. Despite the fact that the monitor power level is more than $20 \mathrm{~dB}$ lower than the laser signal, in eventual self Q-switched regime the energy of pulses can be high enough to damage the detectors. Therefore, the monitor signal was additionally attenuated by combination of fiber taps, example of which is shown in Fig. 1a. Temporal dynamics was detected using InGaAs photodiode with $1.2 \mathrm{GHz}$ bandwidth and displayed by a digital oscilloscope (100 $\mathrm{MHz}$ bandwidth, $1 \mathrm{GSa} / \mathrm{s}$ ). For spectral measurements we used a CCD type spectrometer Ocean Optics HR2000CG-UV-NIR with $1 \mathrm{~nm}$ resolution and also grating-monochromator-based optical spectrum analyzer (OSA).

a)
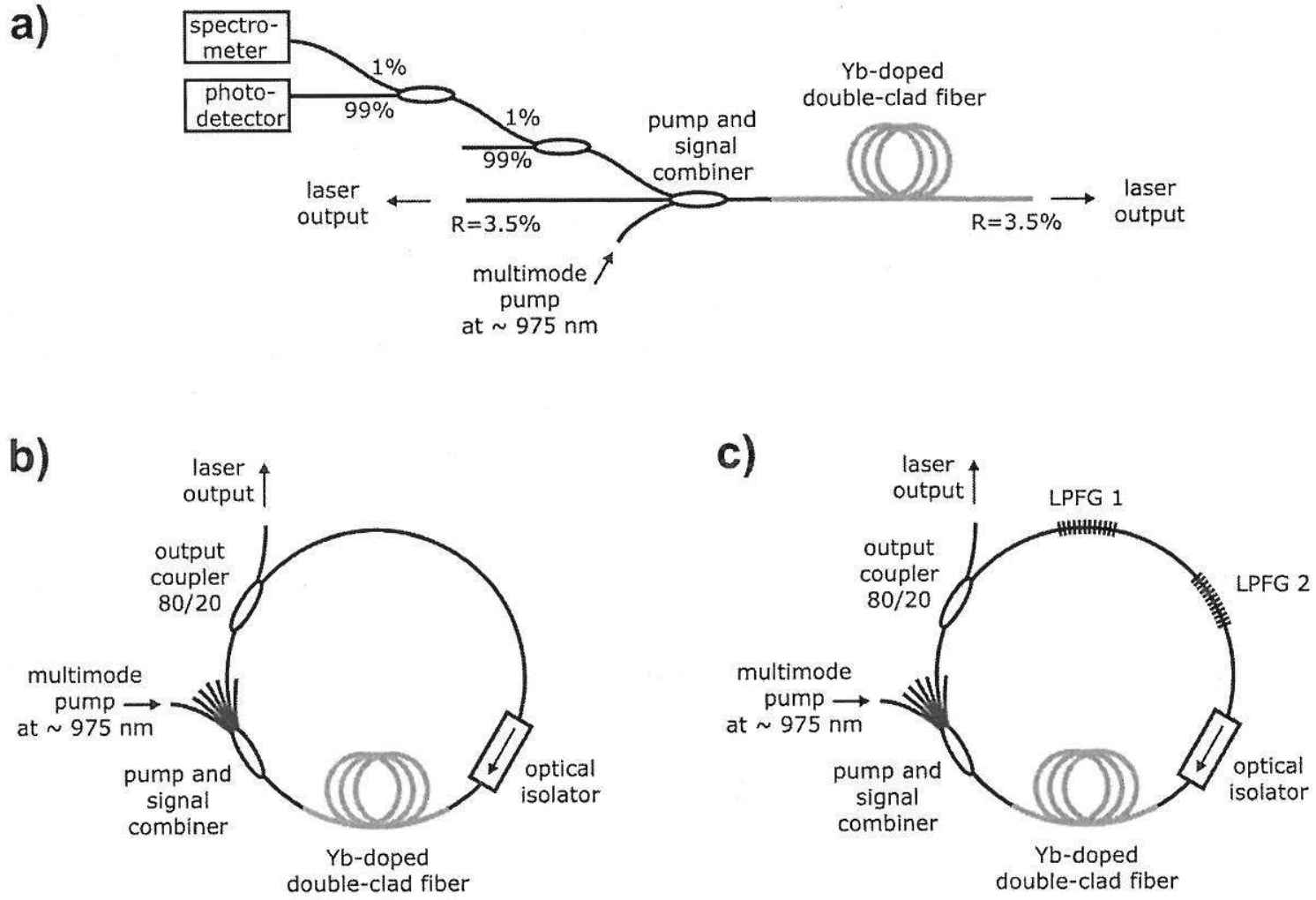

Figure 1. Fiber laser setups in Fabry-Perot cavity (a), ring cavity (b) and ring cavity with two LPFGs (c).

\subsection{Spectra measurement by the CCD-type spectrometer and the Reverse SLLS}

The self-sweeping of the laser wavelength of the Fabry-Perot laser is shown in Fig. 2. Thanks to long sweeping period ( 4.3 seconds in this particular case), the evolution of spectrum during the sweeping can be observed in real-time using relatively cheap CCD-type spectrometer. The sweeping rate dependence on the pump wavelength was observed. The pump laser diode spectrum bandwidth is about $4 \mathrm{~nm}$. The long wavelength edge of the output spectrum of the pump laser diode wavelength vary with the pump current (the rate is about $1.4 \mathrm{~nm} / \mathrm{A}$ ) and with the temperature of the diode case (the rate is about $0.5 \mathrm{~nm} /{ }^{\circ} \mathrm{C}$ ). The pump wavelength increases both with the pump current and the case temperature. With changing the temperature of the pump laser diode from $15^{\circ} \mathrm{C}$ to $40^{\circ} \mathrm{C}$ we have observed that the sweeping rate varies in the range from $5 \mathrm{~nm} / \mathrm{s}$ to $0.9 \mathrm{~nm} / \mathrm{s}$. For the temperature of $40^{\circ} \mathrm{C}$, we have observed even the sweeping of the laser wavelength from longer towards shorter wavelength. It is unlike any of the previous observations [7-9] and [11] where only the sweeping from shorter towards longer wavelength was reported. Therefore, we refer to this process as to 
Reverse SLLS. The laser wavelength temporal sweeps and corresponding relative power values are shown in Figs. 3 to 5 for different settings of the pump laser diode current. The data in Fig. 3-5 were obtained by processing sequences of spectrograms measured by CCD-type spectrometer. In Fig 3, the typical SLLS from shorter towards longer wavelength is shown. The Reverse SLLS is shown in Fig. 4. Note that the maximum power was usually at the shorter wavelength edge. Hence the typical SLLS usually started with maximum power while the Reverse SLLS ended with maximum power. The reverse sweeping was achieved only for limited range of pump powers from the laser threshold at pump power of 230 $\mathrm{mW}$ to the pump power of $310 \mathrm{~mW}$. For the pump power of the upper limit of the Reverse SLLS we have observed transition regime between the two sweeping directions: sweeping towards longer wavelengths and sweeping towards shorter wavelengths, see Fig. 5.

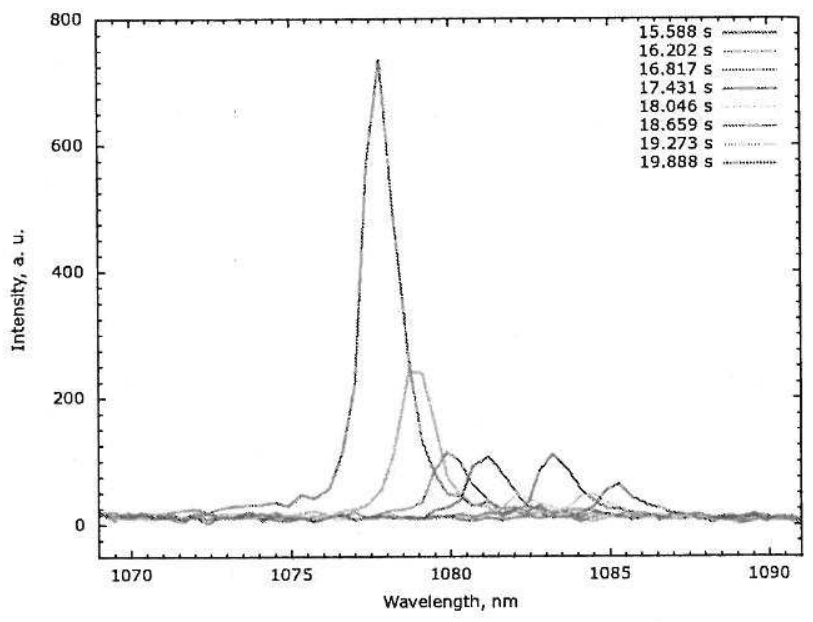

Figure 2. Typical laser spectra at different times during single self-induced laser line sweep. Pump power and laser diode case temperature was $0.67 \mathrm{~W}$ and $25^{\circ} \mathrm{C}$, respectively. The spectra were measured by the CCD-type spectrometer.

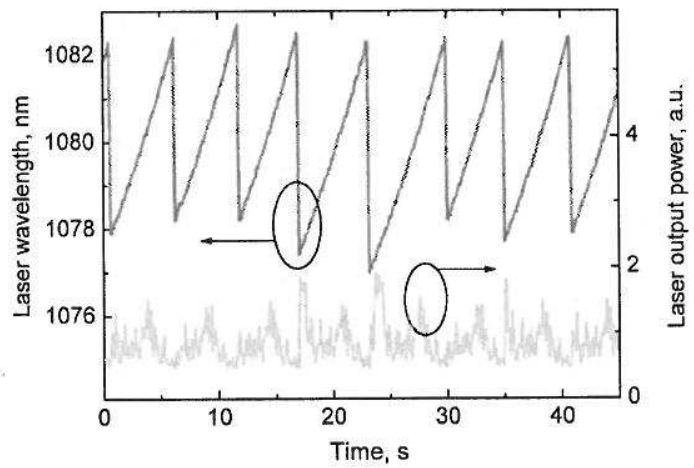

Figure 3. Typical temporal dynamics of the laser wavelength and the peak power for the regime of sweeping towards longer wavelengths. Pump power and laser diode case temperature was $0.38 \mathrm{~W}$ and $40^{\circ} \mathrm{C}$, respectively. The data were collected using spectra measurements by the CCD-type spectrometer. 


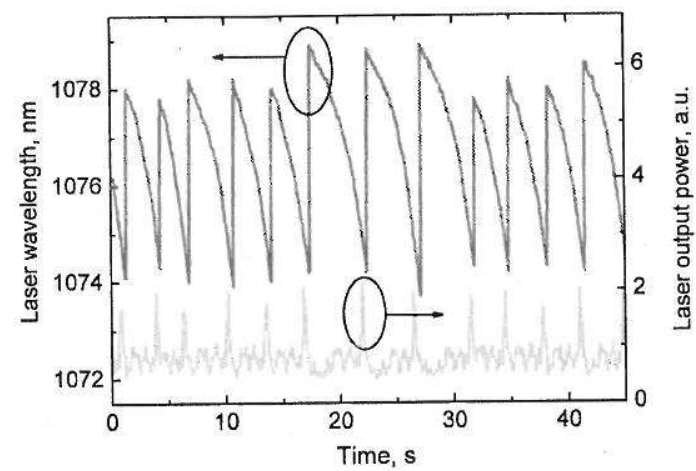

Figure 4. Temporal dynamics of the laser wavelength and the peak power for the regime of sweeping towards shorter wavelengths. Pump power and laser diode case temperature was $0.28 \mathrm{~W}$ and $40{ }^{\circ} \mathrm{C}$, respectively. The data were collected using spectra measurements by the CCD-type spectrometer.

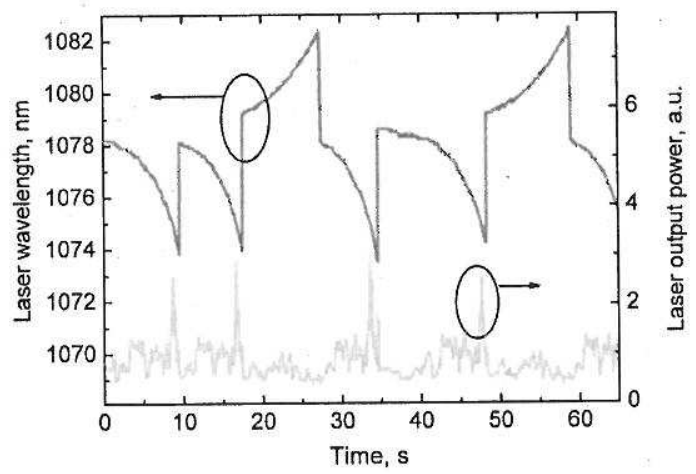

Figure 5. Temporal dynamics of the laser wavelength and the peak power for transition regime between the two sweeping directions: sweeping towards longer wavelengths and sweeping towards shorter wavelengths. Pump power and laser diode case temperature was $0.31 \mathrm{~W}$ and $40^{\circ} \mathrm{C}$, respectively. The data were collected using spectra measurements by the CCD-type spectrometer.

\subsection{Spectra measurements by the grating-type spectrum analyzer and the laser output temporal dynamics}

We detected the SLLS also with a grating-monochromator-based OSA. The OSA spectral measurements are shown in Fig. 6 for the three fiber laser configurations shown in Fig. 1, i.e., Fabry-Perot, ring and ring with the two LPFGs cavities. The measurement takes $44 \mathrm{~s}$ in high-sensitivity mode of the OSA. Spectra for two different pump power levels are shown in Fig. 6 for each laser setup. The spectrum for lower pump power has comb like structure that may indicate a periodic effect with period of the orders of seconds. The spectrum for higher power shows the laser mode of operation beyond the region of the SLLS. While the Fabry-Perot laser was in chaotic self-pulsation regime the ring lasers were in continuous-wave mode. In the case of the ring laser without LPFGS we observed competition of lasing at several wavelengths and the ring laser with the two LPFGs oscillates at single wavelength.

The time periodicity of the laser wavelength drift is clearly manifested when the OSA is set to power meter mode, so that the output at a given wavelength is recorded with time, see Fig. 7. Typical temporal behavior of the laser output detected by the fast InGaAs photodetector is shown in an oscillogram in Fig. 8a. It was recorder for the ring-laser setup with the two LPFGs. Beating between neighboring longitudinal modes of the laser is apparent from the detail of one of the peaks in Fig. $8 \mathrm{~b}$. 


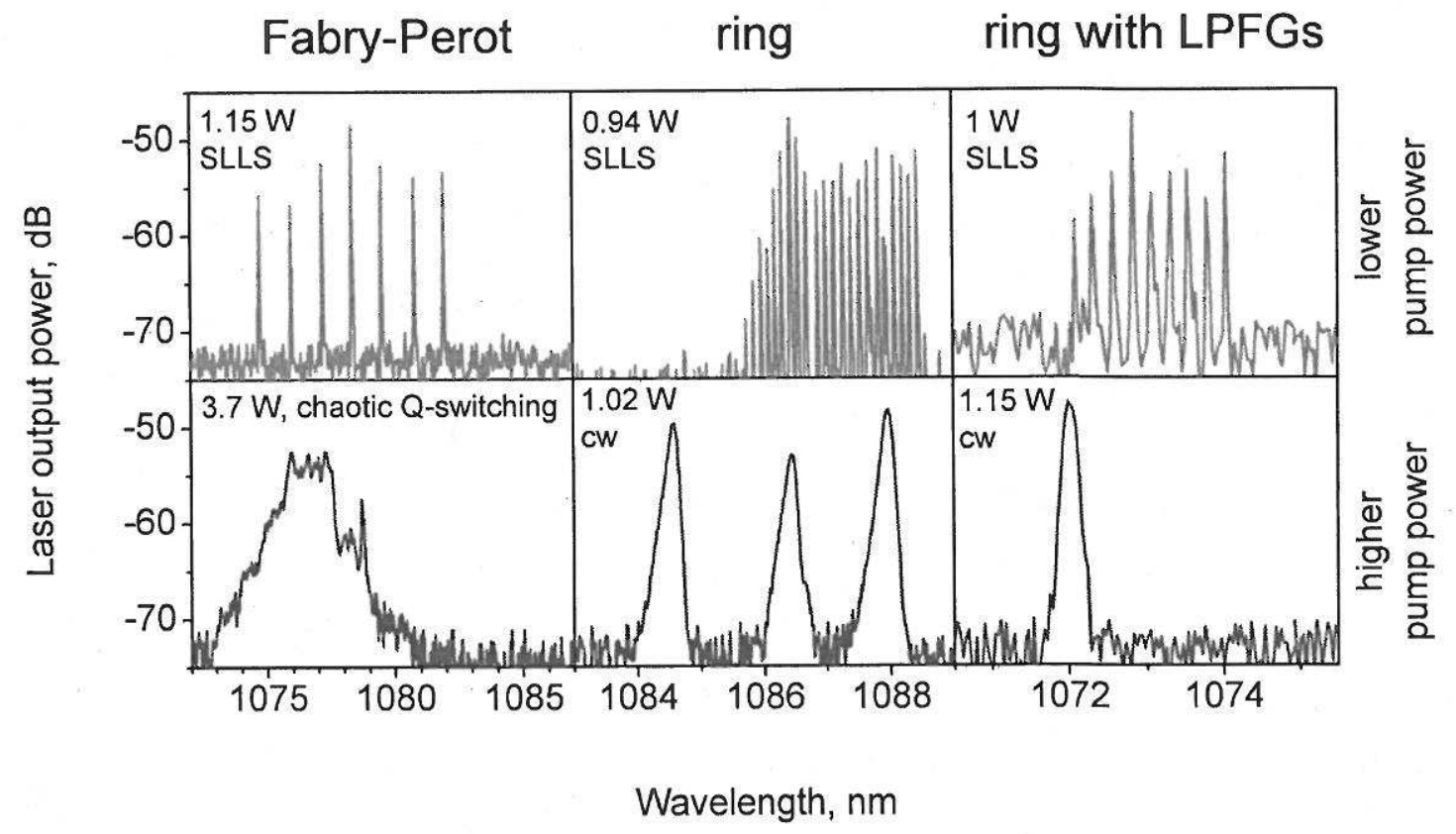

Figure 6. Laser output spectra measured with grating-type optical spectrum analyser for three types of fiber laser cavities: Fabry-Perot, ring, and ring with LPFGs. The upper spectra were taken for the pump power where the SLLS regime occurs while the lower spectra were taken for the pump power outside the SLLS regime. The pump power and regime of the laser is indicated in each graph.

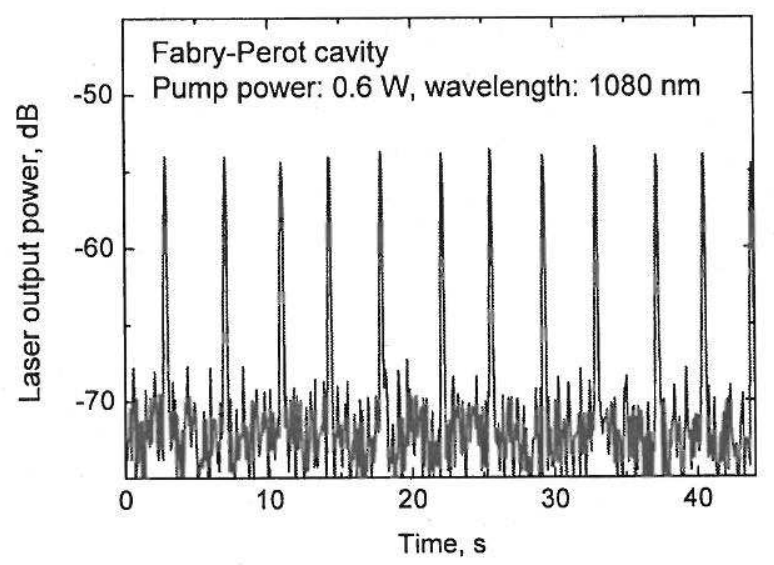

Figure 7. Detection of the sweeping using a power meter mode measurement of the OSA for the Fabry-Perot cavity. 
a)

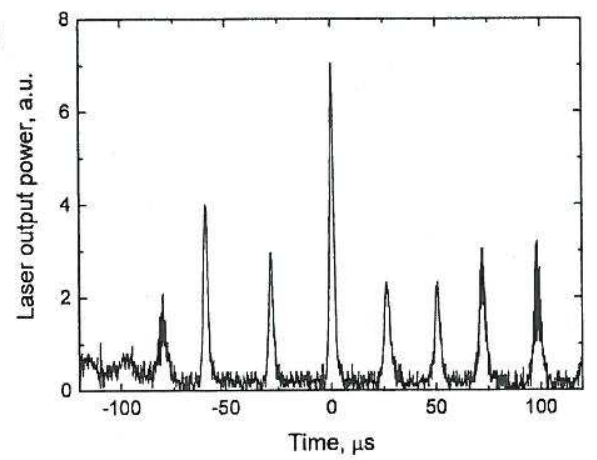

b)

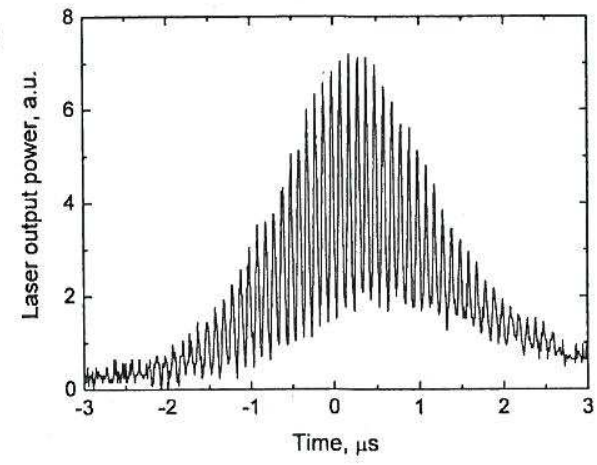

Figure 8. (a) Typical self-pulsing of the fiber laser recorder by oscilloscope, (b) Detail of one of the pulses with apparent fine structure caused by beating of the laser longitudinal modes.

\subsection{SLLS in erbium-doped fiber laser}

Recently, we have observed the SLLS effect in a Fabry-Perot laser tunable at around $1560 \mathrm{~nm}$ based on erbium and ytterbium doped fiber and also core-pumped EDFL. The tunability was achieved by a filter of $3 \mathrm{~nm}$ bandwidth tunable within 1550-1570 nm and the sweeping was observed in $0.5 \mathrm{~nm}$ interval within the filter bandwidth, see Fig. 9. The spectra were measured using OSA ANDO AQ6317B with resolution $10 \mathrm{pm}$. We are now preparing detailed report about the SLLS in EDFL and erbium- and ytterbium-doped fiber laser.

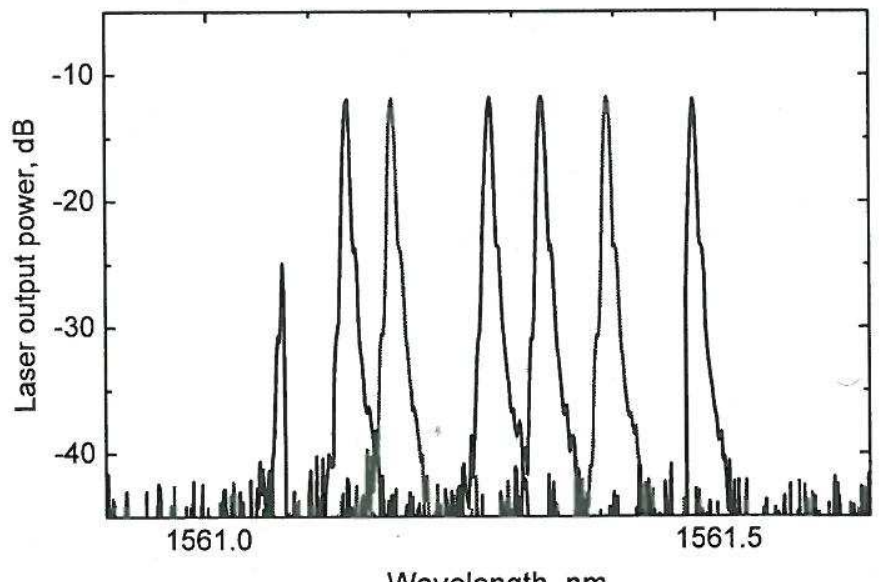

Wavelength, $\mathrm{nm}$

Figure 9. EDFL spectra recorded at seven different moments during the laser line sweeping. The sweeping range of about $0.5 \mathrm{~nm}$ was defined by the tunable filter. 


\section{CONCLUSIONS}

We reported experimental evidence of SLLS in three ytterbium-doped fiber lasers (Fabry-Perot, ring without wavelength selective element and ring laser with LPFG) around $1070 \mathrm{~nm}$ and in an erbium-doped fiber laser around $1560 \mathrm{~nm}$. To our knowledge we have reported for the first time that the sweeping may occur not only from shorter towards longer wavelength but also in the reverse direction: from longer wavelength towards shorter wavelengths.

Particular advantage of the reported swept sources is their simplicity as they do not require any external driving electronics, apart from the pump laser diode driver. We have shown that the SLLS can be detected even with lowresolution, cost-effective CCD-type spectrometer. This fact might promote applications of the SLLS in optical fiber sensor systems.

This work was partially supported by three projects: the French-Czech program Barrande (EGIDE-France, project No. 17360VA and Czech Ministry of Education, Youth and Sports, project No. ME10119); by the Czech Science Foundation project No. GAP205/11/1840, and by the European action COST TD1001 "OFSESA - Novel and reliable optical fibre sensor systems for future security and safety applications" (Czech Ministry of Education, Youth and Sports, project No. LD11030). LPMC is with GIS 'GRIFON' (CNRS, www.unice.fr/GIS).

\section{REFERENCES}

[1] F. Brunet, Y. Taillon, P. Galarneau, and S. LaRochelle, "A simple model describing both self-mode locking and sustained self-pulsing in ytterbium-doped ring fiber lasers", J. Lightwave Technol. 23(6), 2131-2138 (2005).

[2] D. J. Richardson, J. Nilsson, and W. A. Clarkson, "High power fiber lasers: current status and future perspectives [Invited]," J. Opt. Soc. Am. B 27(11), B63-B92 (2010).

[3] D. A. Grukh, A.S. Kurkov, I. M. Razdobreev, A. A. Fotiadi, "Self-Q-switched ytterbium-doped claddingpumped fibre laser", Quantum Electronics 32 (11), 1017-1019 (2002).

[4] B. Dussardier, J. Maria, and P. Peterka, "Passively Q-switched ytterbium- and chromium-doped all-fiber laser", Appl. Opt. 50(25), E20-E23 (2011).

[5] A. S. Kurkov, "Q-switched all-fiber lasers with saturable absorbers", Las. Phys. Lett. 8(5), 335-342 (2011).

[6] P. Peterka, J. Maria, B. Dussardier, R. Slavik, P. Honzatko, and V. Kubecek, "Long-period fiber grating as wavelength selective element in double-clad Yb-doped fiber-ring lasers", Las. Phys. Lett. 6(10), 732-736 (2009).

[7] P. Peterka, P. Navrátil, J. Maria, B. Dussardier, R. Slavík, P. Honzátko, and V. Kubeček, "Self-induced laser line sweeping in double-clad Yb-doped fiber-ring lasers", Las. Phys. Lett., Vol. 9, Published online: March 25, 2012, DOI: 10.1002/lapl.201210013

[8] A. Kir'yanov, and N. Il'ichev, "Self-induced laser line sweeping in an ytterbium fiber laser with non-resonant Fabry-Perot cavity", Las. Phys. Lett. 8(4), 305-312 (2011).

[9] I. A. Lobach, S. A. Babin, S. I. Kablukov, E. V. Podivilov, "Broad-Range Self-Sweeping of a Narrow-Line YbDoped Fiber Laser", In Proc. of 20th International Laser Physics Workshop (LPHYS'11), July 11-15, Sarajevo, Bosnia and Herzegovina, p. 8.1.4 (2011).

[10] P. Peterka and J. Kanka, "Erbium-doped twin-core fibre narrow-band filter for fibre lasers", Opt. and Quantum Electron. 33(4-5), 571-581 (2001).

[11] I. A. Lobach, S. I. Kablukov, E. V. Podivilov, and S. A. Babin, "Broad-range self-sweeping of a narrow-line self-pulsing Yb-doped fiber laser," Opt. Express 19(18), 17632-17640 (2011). 